\title{
Metallographic Procedure to Microstructural Characterization of a Multiphase Steel Applied to Pipelines Industry by Optical Microscopy.
}

\author{
M.S. Pereira,* P.E.L.Garcia,* T.M. Hashimoto* \\ * Department of Materials and Technology, Guaratinguetá Campus, \\ São Paulo State University - UNESP, São Paulo, Brasil, 12500-000
}

Etching is commonly used to reveal microstructural characteristics of steels but does not reveal in a satisfactory way some of the microconstituints available in the structure, mainly when there is the coexistence of them after the thermal or thermomechanical treatments. In the last few years the application of etchants based on picric acid and sodium metabisulfite to reveal bainite and retained austenite have been the main development in etching, aiming a better characterization of these phases by optical microscopy. Moreover, these metallographic results still show inconsistency, specially when quantitative evaluations are considered.

Variations in the metallographic procedure developed by LePera are proposed in this research, mainly in etching, aiming a perfect identification and quantification of the ferrite, bainite, martensite and retained austenite phases in a multiphase steel by optical microscopy. The research was realized in a $0,05 \% \mathrm{C}-0,0021 \% \mathrm{~B}$ microalloyed steel (API-5L-X80), applied to the pipeline industry. The specimens were prepared by grinding (400-2000grit) and polishing (diamond paste 60,25 micron). The etching involved a pre-etch with $2 \%$ Nital $\left(2 \mathrm{~mL}\right.$ of $\mathrm{HNO}_{3}$ to $98 \mathrm{~mL}$ ethanol) for $10 \mathrm{~s}$, in order to outline the grain boundaries, followed by a final etching which consists in a mixture of two solutions based in sodium metabisulfite $\left(10 \mathrm{~g} \mathrm{Na}_{2} \mathrm{~S}_{2} \mathrm{O}_{5}\right.$ to $100 \mathrm{~mL}$ of distilled $\left.\mathrm{H}_{2} \mathrm{O}\right)$ and picric acid ( $4 \mathrm{~g}$ of picric acid to $100 \mathrm{ml}$ of ethanol). The image digital analysis was realized aiming the qualitative and quantitative measurements of the present phases in the microstructure. No types of filters were used to improve the image quality as they could show untrue microstructure or even distort it.

The metallographic procedure showed be quite useful in the microstructural characterization of steels with multiphase structure by optical microscopy, offering considerable contrast among phases which are present in the photomicrography such as when analyzed in gray scale (Fig. 1) as in colors (Fig. 2). According to figure 2, the fair brown areas represent the ferrite matrix, the dark brown ones represent the bainite and the white area represents a martensite as well as the retained austenite. However it is quite an unstable etching, influenced mainly by variations in the etchants volume ratio, in the immersion time of the specimen and in the etching temperature. The best results were obtained with proportions of 12:7 (sodium metabisulfite : acid picric solutions) in about 20s of immersion. The final etching in low temperature, around $0^{\circ} \mathrm{C}$, showed to be quite important in the results reproduction.

\section{References}

[1] P. Jacques et al., Metallurgical Transaction, v.29A, September, 1998, p.2383-93.

[2] E. Girault et al., Materials Characterization, v.40, n.2, 1998, p.111-8.

[3] F. LePera, Journal of Metals, v.32, 1980, p.38-9. 


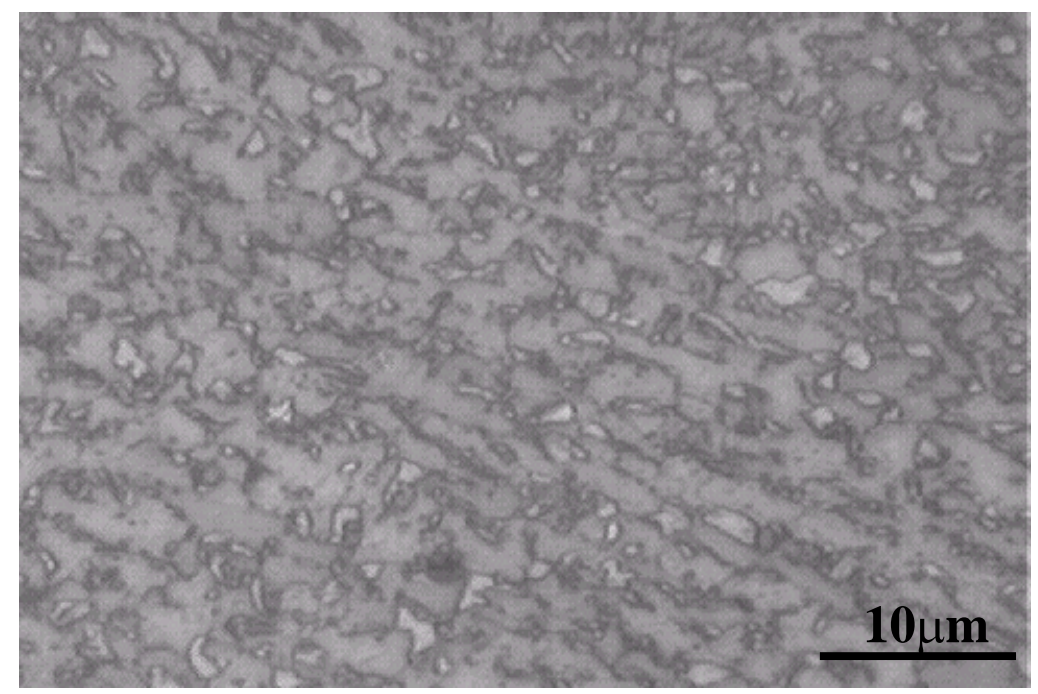

Figure 1. Photomicrography in gray scale of multiphase steel microstructure (API-5L-X80). Etchant: sodium metabisulfite and acid picric solutions (proportions of 12:7).

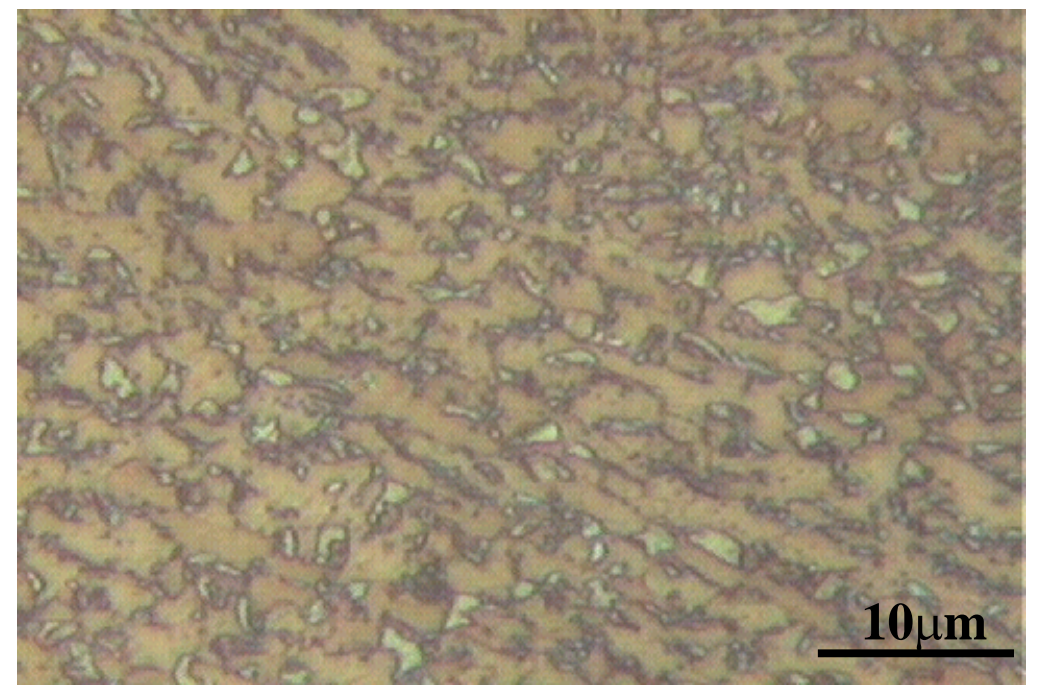

Figure 2. Photomicrography in color of multiphase steel microstructure (API-5L-X80) showing ferrite matrix (brown), bainite (dark brown) martensite plus retained austenite (white). Etchant: sodium metabisulfite and acid picric solutions (proportions of 12:7) 